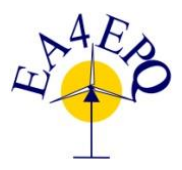

International Conference on Renewable Energies and Power Quality (ICREPQ'17)

Malaga (Spain), $4^{\text {th }}$ to $6^{\text {th }}$ April, 2017

Renewable Energy and Paver Quality. Fournal (RE\&PQJ)

ISSN 2172-038 X, No.15 April 2017

\title{
The influence of the self-excited induction machine into the electrical grid under instability situation - Real case measurement
}

\author{
R. Bosch ${ }^{1}$, P. Casals ${ }^{1}$ and A. Serrano ${ }^{1,2}$ \\ ${ }^{1}$ Department of Electrical Engineering \\ E.T.S.E.I.B, Polytechnic University of Catalonia \\ Diagonal Av. - 647, 0828 Barcelona (Spain) \\ ${ }^{2}$ Electrica Serosense Distribuidora \\ Pol. Ind. Panamà. Ctra. Nac. II Km. 450, 25110 Torres de Segre (Spain)
}

\begin{abstract}
The three phase induction machine is used in the mainly part of the industry and it requires reactive power from the grid to start and function. The reactive power consumption is economically fined so the industries install capacitors in parallel with the motors and loads. The bank capacitor, gives this reactive power to the machine in order to improve the cos $\varphi$ factor in the installation. When a fault appears in the grid, this machine gives the active power to the fault, but when the overcurrent relay sets the fault, the induction machine is already with inertia with electromagnetic and mechanic specific parameters that originate a non-controlled islanding mode and it provides the power to the loads on this feeder. Even though several works are published within the islanding detection, the islanding operation about the induction machine as a generator in power wind energy applications, nevertheless in the following we show the motor perspective. The stability of the system in the time period between the relay opening and the fast reconnection is out of control, so a complete study a about the electric magnitudes, voltage and reactive power, active power and frequency and the angle stability is needed. In this paper we show a real case that appears in a distribution Medium Voltage (MV) radial network in Spain in a $25 \mathrm{kV}$ feeder and we summarize the voltage /current wave form and the frequency oscillation.
\end{abstract}

\section{Key words}

Power Quality, distributed generation, electrical transients, islanding mode, induction machine, non-synchronism situation.

\section{Introduction}

The electrical distribution operators (DO) are responsible of power systems operation in order to guarantee the stability of the electrical system.

When there's a source in a distribution feeder injecting current into the system like distributed generation (DG), the DO have to be aware of the electrical parameters and loads of the system in steady state and it has to manage it.

The issue appears when an electrical load, transiently becomes a generator and it is non-controlled.

The nature of the problem is twofold: on one hand, during the island, there's an unbalanced three phase system, so the loads in this feeder are being fed with a high variable tension wave with the angle and amplitude out of control and on second hand, when the relay closes the circuit there's an out of synchronism reconnection that generates a short-circuit with a high overcurrent.

The growing interest in power quality (PQ), a topic of great importance for future smart grids, GD, that the DO install monitoring tools in order to detect disturbance sources and to control the network. A complete analysis of all disturbances is showed in [1].

In the power generation sources, electrical parameters are specified and regulated by the normative, but in this paper is shown a different type of disturbance that has no regulation.

Our contribution is basically study a real case of islanding situation in an electrical MV distribution network, analyse the phenomena in order to search a solution to this situation.

Thus, the study of this electrical transient is made in the point of common coupling (PCC) between the DO and the industry and viewed from the electrical network, because the large industry parameters of the machine are unknown. 
The previous work was based on location the disturbance source, in a big feeder with large industries and with PV generation presence.

In Fig. 7 is shown the case of study which is formed by two MV feeders, measuring the faults in the $\mathrm{PCC}_{1}$, and measuring the islanding mode in the $\mathrm{PCC}_{2}$.

There are many different methods to detect islanding phenomena in power systems, as for example [2] and [3].

The protection relay and the stability system in islanding situation has been studied by many authors, as for example in [4] and [5].

It can be affirmed that the stability of the system is twofold, on the on hand Reactive Power and Voltage (QV) and in the other hand Active Power and Frequency (Pf) [6], [7] .

In the following, we study all the process due to the transient behaviour of the induction machine viewed from the network. The events showed in this paper were recorded with a different power quality analysers; Elspec PQ Box in the $\mathrm{PCC}_{2}$ and from a PQ function of the substation protection relay, Ekor RPS made by Ormazabal and powered by Ingeteam in $\mathrm{PCC}_{1}$.

2. Mathematical model of the self-excited induction machine in the abc-reference frame

\section{A. The mathematical model}

The general model of the induction machine is given in (1) and (2) by the following differential equations for the stator and the rotor voltages:

$v=r \cdot i+\frac{d \lambda}{d t}$

$\frac{d v}{d t}=-\frac{1}{C} \cdot i$

The matrix expression of (1) is showed in (3):

$\left[\begin{array}{c}\mathrm{V}_{\mathrm{S}} \\ \mathrm{V}_{\mathrm{r}}^{\prime}\end{array}\right]=\left[\begin{array}{cc}\mathrm{r}_{\mathrm{S}} & 0 \\ 0 & \mathrm{r}_{\mathrm{r}}^{\prime}\end{array}\right]\left[\begin{array}{c}\mathrm{i}_{\mathrm{s}} \\ \mathrm{i}_{\mathrm{r}}^{\prime}\end{array}\right]+\frac{d}{d t}\left[\begin{array}{c}\lambda_{\mathrm{s}} \\ \lambda_{\mathrm{r}}^{\prime}\end{array}\right]$

The matrix expression of (2) is showed in (4):

$$
\frac{d}{d t}\left[\mathrm{v}_{\mathrm{S}}\right]=-\frac{1}{\mathrm{C}}\left[\mathrm{i}_{\mathrm{S}}\right]
$$

In the abc-reference frame, the matrix of the stator and rotor resistances are given by:

$$
\begin{aligned}
& \mathrm{r}_{\mathrm{s}}=\left[\begin{array}{ccc}
r_{a s} & 0 & 0 \\
0 & r_{b s} & 0 \\
0 & 0 & r_{c s}
\end{array}\right] \\
& \mathrm{r}_{\mathrm{r}}^{\prime}=\left[\begin{array}{ccc}
r_{a r}^{\prime} & 0 & 0 \\
0 & r_{b r}^{\prime} & 0 \\
0 & 0 & r_{c r}^{\prime}
\end{array}\right]
\end{aligned}
$$

The flux linkages for the stator and rotor winding can be expressed as:

$$
\left[\begin{array}{l}
\lambda_{\mathrm{s}} \\
\lambda_{\mathrm{r}}^{\prime}
\end{array}\right]=\left[\begin{array}{cc}
\mathrm{L}_{\mathrm{Ss}} & \mathrm{L}_{\mathrm{sr}}^{\prime} \\
\mathrm{L}_{\mathrm{rs}}^{\prime} & \mathrm{L}_{\mathrm{rr}}^{\prime}
\end{array}\right]\left[\begin{array}{c}
\mathrm{i}_{\mathrm{s}} \\
\mathrm{i}_{\mathrm{r}}^{\prime}
\end{array}\right]
$$

Finally the matrices for the winding inductances are defined as:

$\mathrm{L}_{\mathrm{ss}}=\left[\begin{array}{ccc}L_{l s}+L_{m s} & -\frac{1}{2} L_{m s} & -\frac{1}{2} L_{m s} \\ -\frac{1}{2} L_{m s} & L_{l s}+L_{m s} & -\frac{1}{2} L_{m s} \\ -\frac{1}{2} L_{m s} & -\frac{1}{2} L_{m s} & L_{l s}+L_{m s}\end{array}\right]$

$$
\mathrm{L}_{\mathrm{rr}}^{\prime}=\left[\begin{array}{ccc}
L_{l r}^{\prime}+L_{m r} & -\frac{1}{2} L_{m r}^{\prime} & -\frac{1}{2} L_{m r}^{\prime} \\
-\frac{1}{2} L_{m r}^{\prime} & L_{l r}^{\prime}+L_{m r} & -\frac{1}{2} L_{m r}^{\prime} \\
-\frac{1}{2} L_{m r}^{\prime} & -\frac{1}{2} L_{m r}^{\prime} & L_{l r}^{\prime}+L_{m r}
\end{array}\right]
$$

$$
\mathrm{L}_{\mathrm{sr}}^{\prime}=L_{m s}\left[\begin{array}{ccc}
\operatorname{Cos}\left(\theta_{r}\right) & \operatorname{Cos}\left(\theta_{r}+\frac{2 \pi}{3}\right) & \operatorname{Cos}\left(\theta_{r^{-}} \frac{2 \pi}{3}\right) \\
\operatorname{Cos}\left(\theta_{r^{-}} \frac{2 \pi}{3}\right) & \operatorname{Cos}\left(\theta_{r}\right) & \operatorname{Cos}\left(\theta_{r}+\frac{2 \pi}{3}\right) \\
\operatorname{Cos}\left(\theta_{r}+\frac{2 \pi}{3}\right) & \operatorname{Cos}\left(\theta_{r^{-}} \frac{2 \pi}{3}\right) & \operatorname{Cos}\left(\theta_{r}\right)
\end{array}\right]
$$

$\mathrm{L}_{\mathrm{rs}}^{\prime}=L_{m s}\left[\begin{array}{ccc}\operatorname{Cos}\left(\theta_{r}\right) & \operatorname{Cos}\left(\theta_{r}-\frac{2 \pi}{3}\right) & \operatorname{Cos}\left(\theta_{r}+\frac{2 \pi}{3}\right) \\ \operatorname{Cos}\left(\theta_{r}+\frac{2 \pi}{3}\right) & \operatorname{Cos}\left(\theta_{r}\right) & \operatorname{Cos}\left(\theta_{r}-\frac{2 \pi}{3}\right) \\ \operatorname{Cos}\left(\theta_{r}-\frac{2 \pi}{3}\right) & \operatorname{Cos}\left(\theta_{r}+\frac{2 \pi}{3}\right) & \operatorname{Cos}\left(\theta_{r}\right)\end{array}\right]$

Thus, the relation of the self-inductances matrix is showed in (12): 
$\mathrm{L}_{\mathrm{sr}}^{\prime}\left(\theta_{\mathrm{r}}\right)=\left[\mathrm{L}_{\mathrm{rs}}^{\prime}\left(\theta_{\mathrm{r}}\right)\right]^{T}$

Where $\theta_{r}$ is the angle rotor, $L_{l s}$ is the stator winding leakage inductance per phase $L^{\prime}{ }_{l r}$ the rotor winding leakage inductance per phase, $L_{m s}$ is the self-inductance for the stator winding, the $L_{m r}$ is the the self-inductance for the rotor winding.

The superscript 'denotes magnitudes that are referred to the rotor.

The electromagnetic torque of the induction machine is given by the expression:

$T_{e m}(t)=\mathrm{i}_{\mathrm{s}}^{T} \frac{d}{d \theta r}\left[\mathrm{~L}_{\mathrm{sr}}^{\prime}\right]\left[\mathrm{i}^{\prime}{ }_{\mathrm{r}}\right]$

Where $i_{s}$ represents the space vector stator currents in abc reference and the $i_{r}^{\prime}$ the space vector rotor currents in abc reference.

The mechanic equations referred to the classical dynamics theory are given by:

$T_{e m}-T_{l}=J \frac{d \omega m}{d t}$

$$
\omega_{m}=\frac{d \theta m}{d t}
$$

Where $T_{l}$ is the load torque, $J$ the inertia moment of the rotor and mechanic load expressed in $\mathrm{kgr} \cdot \mathrm{m}^{2}$. The inertia constant $H$ of the machine is given in (16):

$H=\frac{1}{2} \cdot \frac{J \cdot \omega^{2}}{s \cdot p^{2}}$

The slip in the induction machine is calculated as in (17):

$\frac{d S}{d t}=\frac{T_{e m}-T_{l}}{t_{m}}$

When $t_{m}$ is a mechanical time constant.

In the fig 1. is shown the model of the self-excited induction motor in the abc reference-frame.

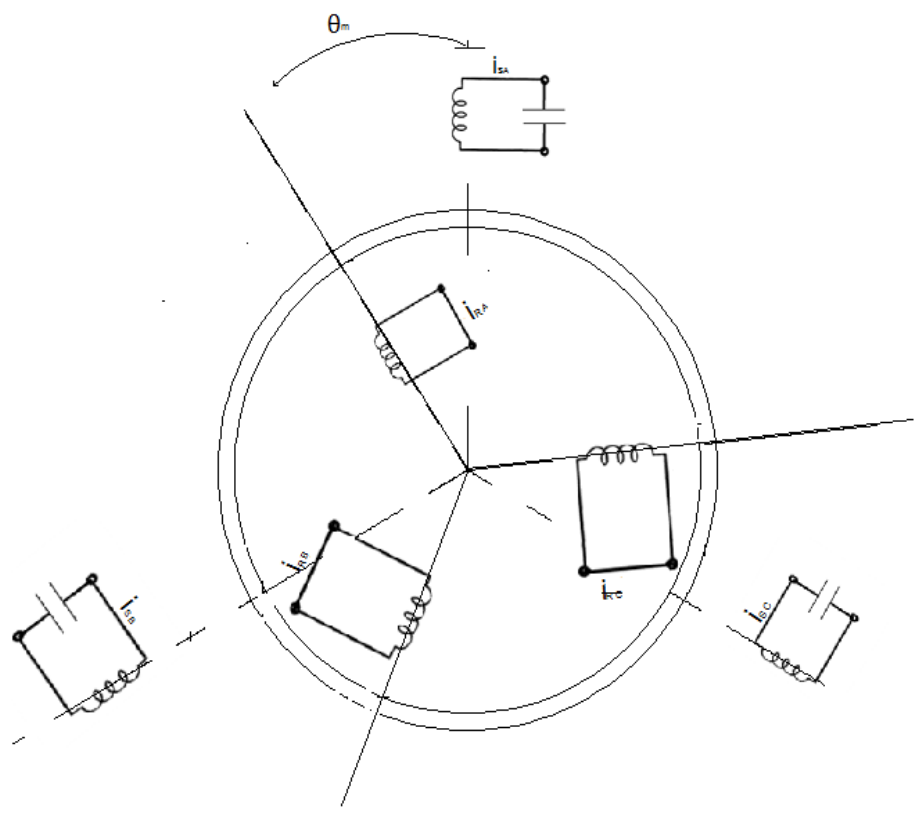

Figure 1.Self-excited Induction motor in the abc-reference frame.

\section{B. Model of the system grid-load}

The model of the self-excited induction machine integrated in an electrical utility is showed in Fig.2:

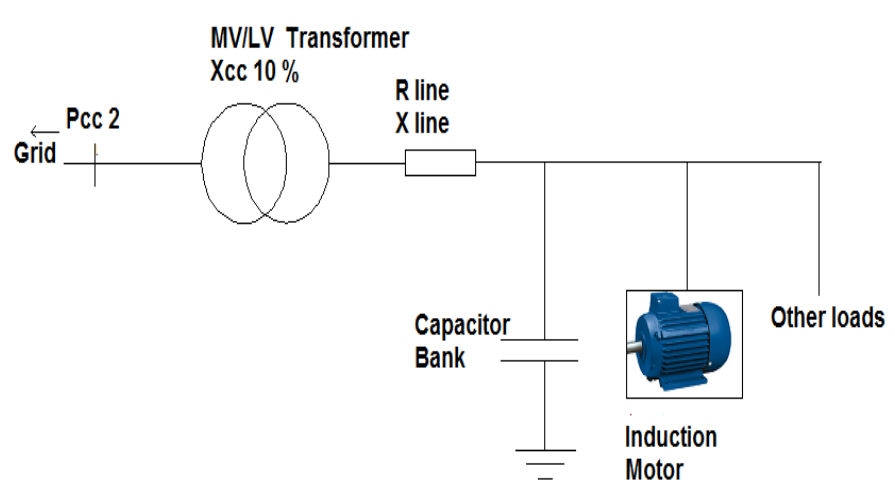

Figure 2.Equivalent circuit of the large industry with the Induction machine

\section{Operation Time Sequences}

Behavioural effects of the induction machine into the electrical grid, are analysed from the beginning, starting with a pre-fault situation in steady state, the faulted system, the islanding situation and finally the out of phase reconnection.

\section{A. Steady state, short circuit and breaker opening}

The load flow in steady state is calculated by PSS-SINCAL [13]. 
Initially the motor in $\mathrm{PCC}_{2}$ is receiving the instantaneous active power $\mathrm{P}(\mathrm{t})$ from the grid and the instantaneous reactive power $\mathrm{Q}(\mathrm{t})$ from the capacitor bank.

In the Fig. 3 and fig. 4 is showed the pre-fault situation:
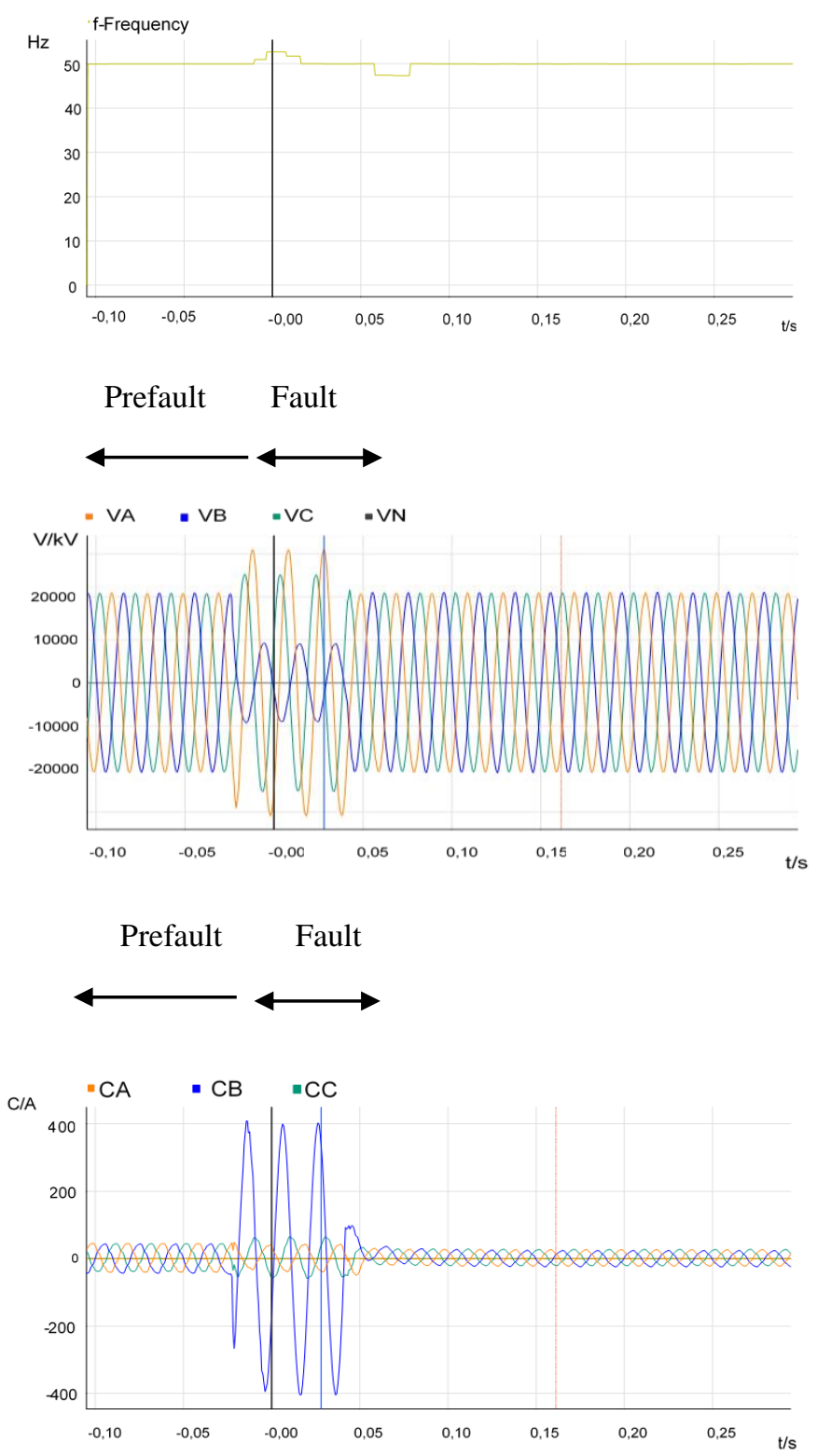

Figure 3. The frequency, and the voltage/current wave at $\mathrm{PCC}_{1}$

As can be seen in the fig. 3 an L-G short circuit appears in the feeder 1 and the overcurrent protection set the fault within 60 ms. We appreciate that the current value, at steady-state, go down from $44 \mathrm{~A}$ to $26 \mathrm{~A}$ due to the overcurrent relay aperture.

J.C.Das analysed this situation in [8].

The duration of the short circuit produces a voltage sag in one phase, as we known is type B [9] see Fig. 2.
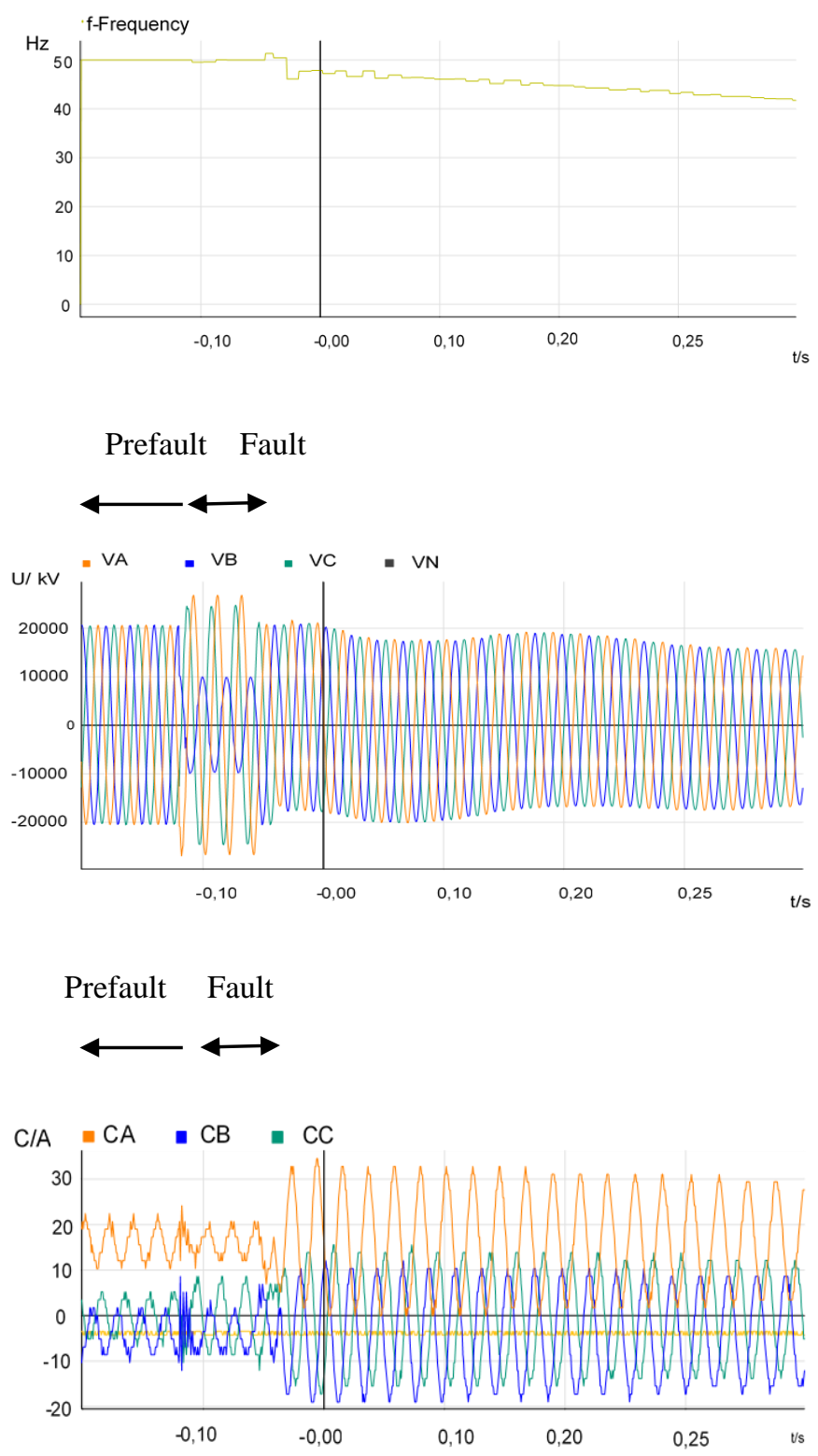

Figure 4. The frequency, and the voltage/current wave at $\mathrm{PCC}_{2}$

The duration of the fault is $60 \mathrm{~ms}$.

We observe that after the breaker opening, the islanding phenomena appears, thereby, the frequency goes down because the $\frac{d \omega m}{d t}$ is decreasing.

When the fault is set, the induction motor reaccelerates [10] .

\section{B. Islanding situation}

The islanding developed by the induction motors is absolutely non-controlled, so because of that we have disturbances on the frequency value and in the voltage and current wave. 
On the one hand the induction motor supply the voltage wave amplitude but the angle is unstable, so the reference QV is not enough to supply the reactive power to system loads.

On the other hand, the reference Pf, due to the angular velocity decreases is either unstable, so it couldn't supply active power to system loads.

In the fig. 4 is showed the islanding situation in the $\mathrm{PCC}_{2}$.
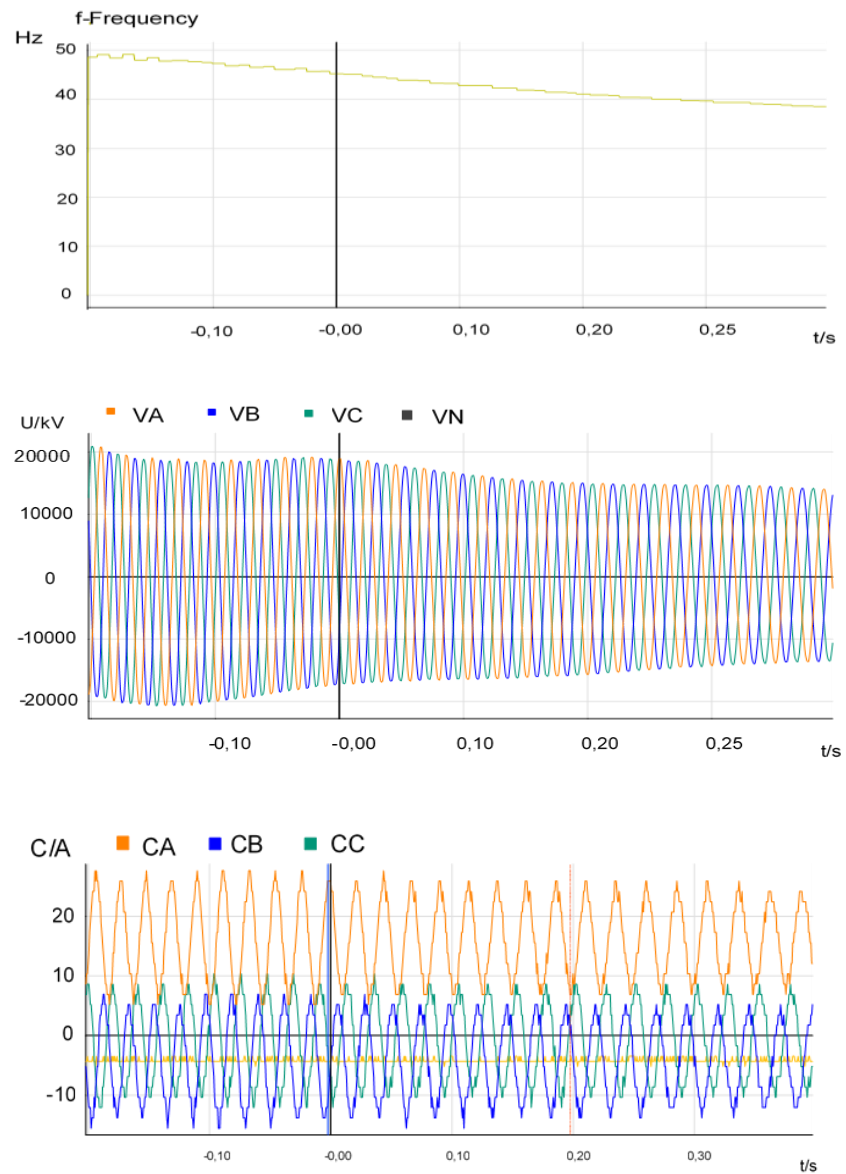

Figure 5. The frequency, and the voltage/current wave at $\mathrm{PCC}_{2}$

\section{Out of phase reconnection}

The protection relay has automatic reconnections programmed, so the protection closes the circuit after defined $\mathrm{T}_{1}$.

As we observe in Fig.6, after this time $T_{1}=1,3 \mathrm{~s}$, appears a superposition between two different voltage waves, one of them at $50 \mathrm{~Hz}$ from the grid and the other by the feeder with the induction motors at $32 \mathrm{~Hz}$.

The studies of this type of transients are showed in [11] - [12].
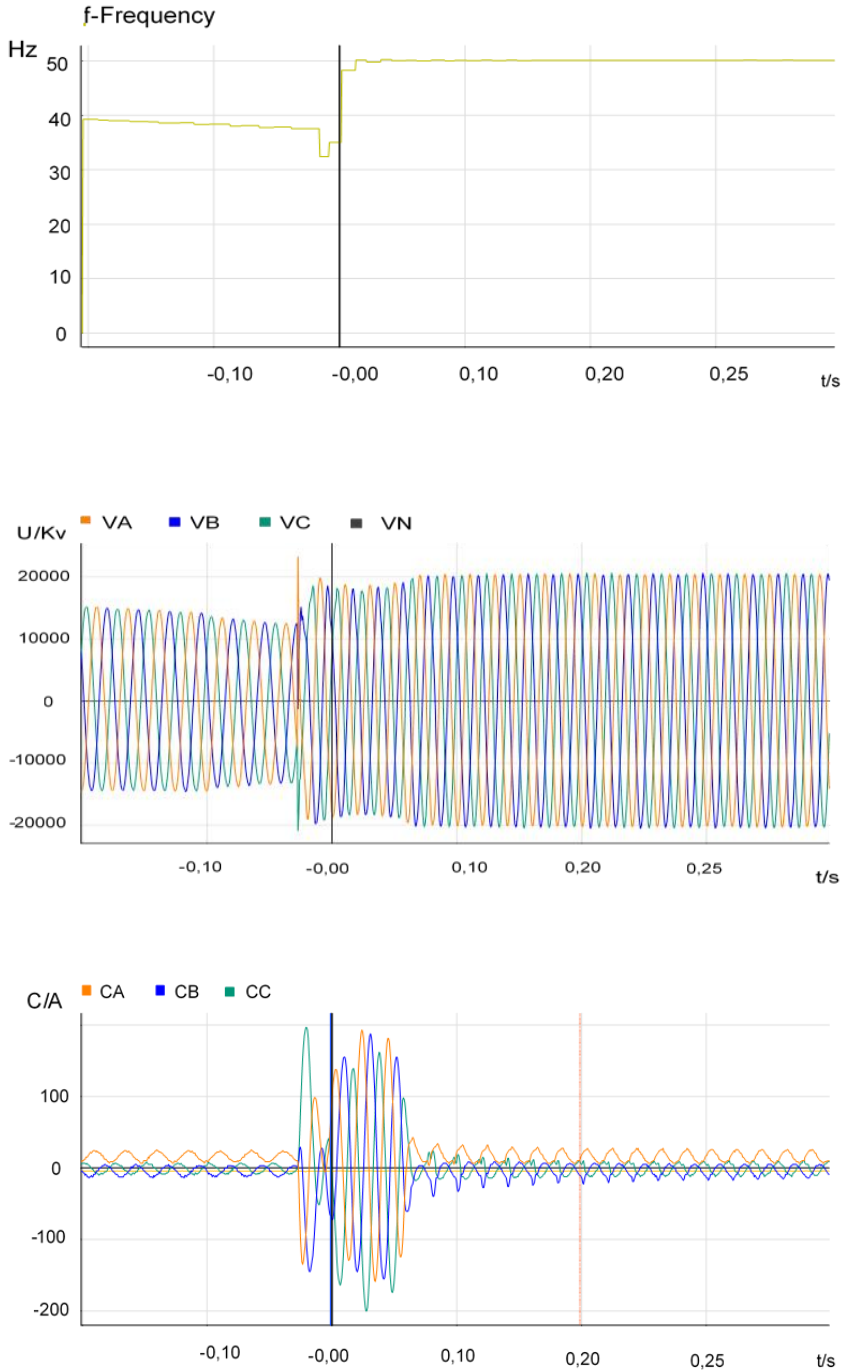

Figure 6 . The frequency, and the voltage/current wave at PCC2

In the current wave showed in Fig.6 we observe that the overcurrent transient appears. In this case, it takes 5 times the nominal current value, moreover this three phase overcurrent produces a shallowness and brief three phase sag type A [9].

\section{Case of study analysed}

The case of study is focused in a distribution network that operates radially in a grounded system with an infeeder at MV level, connected to the principal busbar, with two feeders and at same time end-users of each are connected to it through Dyn transformers as shown in fig. (7): 


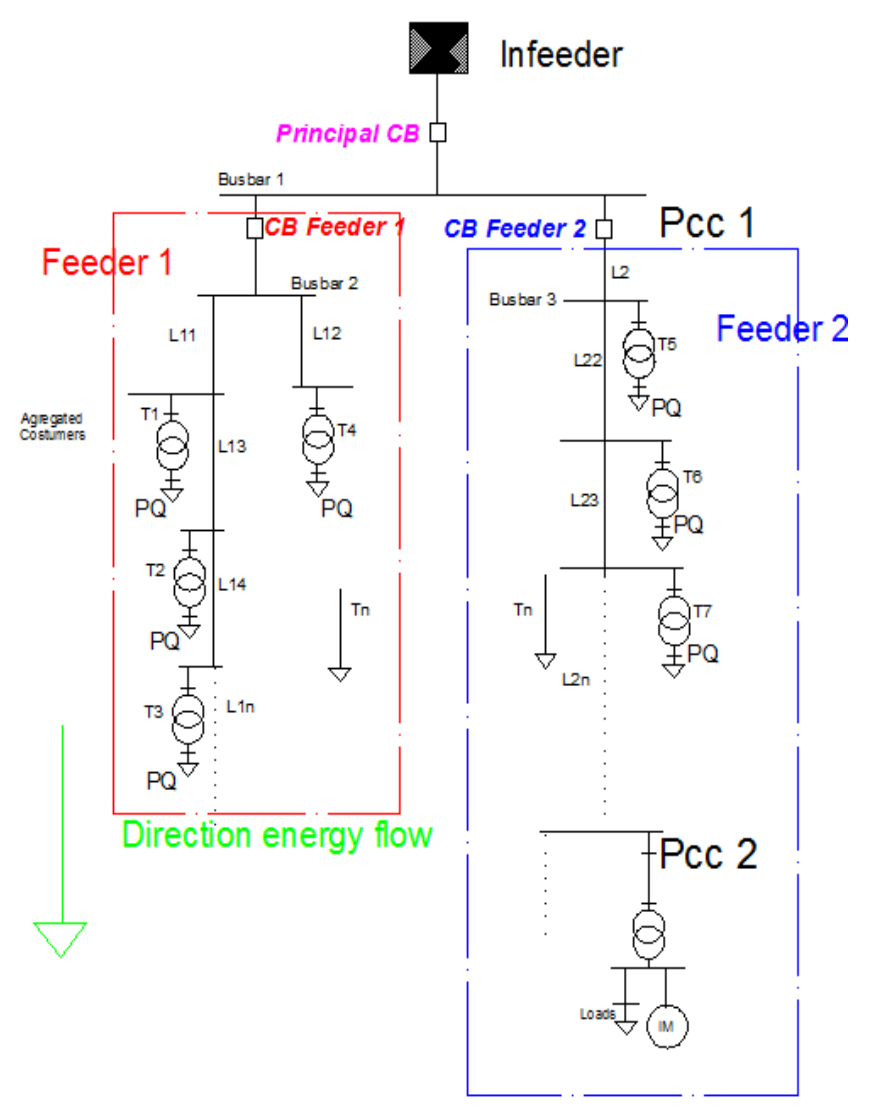

Figure 7. Single line diagram of the network analysed.

The nominal values and the essential parameters of the grid are shown in Table 1:

\begin{tabular}{|c|c|c|c|}
\hline $\begin{array}{l}\text { Nominal } \\
\text { Values }\end{array}$ & & $\begin{array}{l}\text { Line } \\
\text { values }\end{array}$ & $\Omega / \mathrm{km}$ \\
\hline $\mathrm{U}$ & $25 \mathrm{kV}$ & $\mathrm{R}_{\mathrm{LA} 30}$ & 1,07 \\
\hline $\mathrm{f}$ & $50 \mathrm{~Hz}$ & $\mathrm{X}_{\mathrm{LA} 30}$ & 0,441 \\
\hline $\mathrm{S}_{\mathrm{cc}} \mathrm{PCC}_{2}$ & 85 Mva & $\mathrm{R}_{\mathrm{LA} 56}$ & 0,687 \\
\hline $\mathrm{S}_{\mathrm{cc}} \mathrm{PCC}_{2}$ & $80 \quad$ Mva & $\mathrm{X}_{\mathrm{LA} \mathrm{56}}$ & 0.416 \\
\hline$S_{\text {feeder } 1}$ & 1,5 Mva & $\mathrm{R}_{\mathrm{LA} 110}$ & 0.306 \\
\hline$S_{\text {feeder } 2}$ & 2 Mva & $\mathrm{X}_{\mathrm{LA} 110}$ & 0.405 \\
\hline
\end{tabular}

Table 1. Summary of nominal values and parameters

The values of voltage are measured with neutral reference, so that the max value is $\mathrm{U}_{\max }=20,4 \mathrm{kV}$.

\section{Conclusions}

By analysing the oscillography, we can conclude that the induction motor loads in presence of capacitors, surely develop a self-excited situation so depending on its inertia parameters could appear this phenomena.

This paper revealed that a new perspective regulation is needed. The programmed fast reconnection time affect directly to the transient overcurrent. To provide a solution to this problem once is detected, we propose two options, on the one hand to install a synchronism check relay at PCC of the aggregated costumer and on the second hand to prolong the time of the first reconnection in the overcurrent relay.

The aforementioned islanding situation and the out of synchronism reconnection damage the electrical network loads and its switchgear and protection.

This article pretend to open up new research line to the distribution electrical networks that has the presence of large industries.

Future developments on this topic will focus on parameter determination, a model validation by simulation of the stability system and finally the influence of the type fault on the islanding situation.

\section{References}

[1] M. Donsión, Pérez, La calidad de la energia eléctrica. Garceta Grupo Editorial, 2016.

[2] A. R. Di Fazio, G. Fusco, and M. Russo, "Islanding detection method based on a Thevenin-like model," IET Gener. Transm. Distrib., vol. 9, no. 13, pp. 17471754, 2015.

[3] F. Ji, Y. Li, J. Xiang, and S. Liu, "Islanding detection method based on system identification," IET Power Electron., vol. 9, no. 10, pp. 2095-2102, 2016.

[4] S. Li, K. El-Arroudi, G. Joós, and A. J. Rodolakis, "Islanding protection of multiple distributed resources under adverse islanding conditions," IET Gener.

Transm. Distrib., vol. 10, no. 8, pp. 1901-1912, 2016.

[5] R. Anne, F. Katha Basha, R. Palaniappan, K. L. Oliver, and M. J. Thompson, "Reliable Generator Islanding Detection for Industrial Power Consumers With On-Site Generation," IEEE Trans. Ind. Appl., vol. 52, no. 1, pp. 668-676, 2016.

[6] A. R. Bergen and V. Vittal, Power Systems Analysis. Prentice Hall, 2000.

[7] A. Exposito, Gómez, Análisis y operación de sistemas de energia eléctrica, Mac. McGraw-Hill,2002.

[8] J. C. Das, "Effects of Momentary Voltage Dips on the Operation of Induction and Synchronous Motors," IEEE Trans. Ind. Appl., vol. 26, no. 4, pp. 711-718, 1990.

[9] M. H. Bollen, Understanding Power Quality Problems: Voltage Sags and Interruptions. Wiley, 2000.

[10] M. H. J. Bollen, "Influence of motor reacceleration on voltage sags," IEEE Trans. Ind. Appl., vol. 31, no. 4, pp. 667-674, 1995.

[11] F. P. De Mello and G. W. Walsh, "Reclosing

Transients in Induction Motors with Terminal Capacitors," AIEE Rotating Mach. Comm., 1961.

[12] C. Wagner, "Self-excitation of induction motors with series capacitors," Trans. Am. Inst. Electr. Eng., vol. 60, no. 12, pp. 1241-1247, 1941.

[13] Siemens PSS-SINCAL "Power systems analysis Software" Available: https://www.siemens.com 